\title{
El metajuego y la subversión de la narrativa tradicional en The Stanley Parable
}

\author{
Laksmy Irigoyen Regueiro*
}

RESUMEN: The Stanley Parable es un ejemplo magistral de metajuego, por medio del cual se realiza una reflexión paródica sobre el lenguaje videolúdico y su diferencia con la narrativa tradicional. Con este artículo se pretende llevar a cabo una aproximación al tema central de este título -el metajuego y la interactividad del jugador-, partiendo para ello de la teoría de los frames ontológicos y de la constitución del Círculo Mágico a través de estos. De esta manera, comprobaremos como se produce un constante cambio de marco de realidad por medio de la voz del Narrador, mediante lo cual podemos observar la dicotomía jugador/personaje, marcada por la agencia.

PALABRAS CLAVE: Metajuego. Game Studies. Ludología. Círculo Mágico. The Stanley Parable.

"Al principio Stanley asumió que había roto el mapa, hasta que oyó esta narración y se dio cuenta de que era parte del diseño del juego. Entonces admiró al juego por su profundo e ingenioso comentario sobre la naturaleza de la estructura en videojuegos y su examinación de clichés de estructuras narrativas."

Narrador (The Stanley Parable, Galactic Cafe, 2013)

\section{Introducción}

The Stanley Parable (GALACTIC CAFE, 2013) es una aventura conversacional experimental en primera persona, desarrollada por Davey Wreden, con un planteamiento muy original. El juego comienza con la voz en off del Narrador, relatando el día a día de Stanley en la oficina. Este recibe órdenes a través de su ordenador sobre que teclas debe pulsar, sin que llegue jamás a cuestionarlas. Sin embargo, como indica el Narrador, un día dejó de recibirlas, y Stanley decide

\footnotetext{
* Universidade de Santiago de Compostela, Santiago de Compostela, Galiza, España. E-mail: laksmyirigoyenregueiro@hotmail.com
} 
abandonar su oficina para descubrir qué ha ocurrido. El jugador adquiere el control del personaje en ese momento y debe ir realizando las acciones que el Narrador va indicando. A medida que el personaje va encontrando disyuntivas seguir uno u otro camino, realizar una u otra acción, etc.-, el jugador puede decidir si seguir las instrucciones del narrador o no. En caso de que decida cambiar la historia que está siendo narrada, el Narrador se irá enfadando y conducirá al personaje a un final desastroso.

Lo más interesante de este título es que constituye un ejemplo magistral de metajuego, puesto que el Narrador rompe la cuarta pared en numerosas ocasiones, haciendo referencias al lenguaje videolúdico y empleando la intertextualidad. Se trata, pues, de una revisión crítica e irónica de los videojuegos, de su desarrollo, y del papel de los propios jugadores. Así, el Narrador es consciente en todo momento que se encuentra en un juego, llegando a acusar a Stanley de estar manejado por una persona del mundo real. Sin embargo, y a pesar de realizar referencias casi constantes a la historia como tal, al personaje o al jugador, el proceso de inmersión no se rompe al realizarse constantes cambios en los frames del Círculo Mágico, el que es definido por Markus Montola como "a social and cultural structure that contains endogenous meaning within." (MONTOLA, 2012, p. 51)

Con este artículo se pretende analizar The Stanley Parable a partir del establecimiento de los tres frames que constituyen el Círculo Mágico (MONTOLA, 2012; STENROS, 2014), para comprobar como se subvierte la linealidad de la narrativa tradicional por medio de la agencia del jugador. Este tema es uno de los puntos centrales del juego, el que, como veremos, se articula brillantemente por medio de la oposición Stanley-Narrador. Para llevar a cabo este estudio se ha jugado sobre ocho horas con el juego, con lo que se han llegado a experimentar quince finales diferentes. A partir de esta experiencia directa, se han aplicado las teorías indicadas al mismo, como manera de comprobar como se construye la disyuntiva entre la narrativa tradicional y la agencia de los jugadores que se puede observar en este título. 


\section{Marco Teórico: El Círculo Mágico}

Los juegos, como cualquier otra actividad performativa, pueden ser analizados por medio de los frames estudiados por Goffman y Bateson, teoría recogida y aplicada a los juegos por diversos investigadores, como Markus Montola o Jaakko Stenros. De esta manera, podemos partir de tres frames de realidad diferenciada, mediante los cuales se establecerá el Círculo Mágico en el que se desenvolverá el juego. Este se conforma mediante la negociación y la metacomunicación entre los participantes, de manera que cambiará a lo largo del proceso de jugar. Por lo tanto, podemos afirmar que la relación entre la mentalidad lúdica y el acto de jugar se consigue por la negociación social y la estructuración compartida de un juego (MONTOLA, 2012, pp. 48-49; STENROS, 2014, p. 174).

Así, se establece una dimensión espacio-temporal con un carácter que va más allá de la frontera física. Las reglas del juego, como elementos sociales compartidos que deben ser aceptados por los participantes, marcarán en un primer momento la constitución del Círculo Mágico y, con cada negociación de las mismas, se puede producir una modificación en el concepto previamente establecido.

Bateson nos indica que es la metacomunicación el elemento que confiere el marco en el cual se desenvuelve el juego. De esta forma, las acciones efectuadas durante el acto de jugar no denotarán lo mismo que si estas se producen en otro contexto (BATESON, 1987, pp. 185-186). Para ilustrar este hecho, Bateson pone el ejemplo de unos simios jóvenes, los que, cuando juegan, realizarán una serie de secuencias interactivas muy semejantes a las empleadas durante un combate. Sin embargo, lo que estas acciones representan en un marco lúdico es muy distinto a lo que representarían en un contexto de confrontación. Así, la significación de la actividad es otorgada mediante la metacomunicación, constituyéndose, por lo tanto, como social. ${ }^{1}$

1 Cabe destacar que si bien Bateson considera la metacomunicación social, indica que el marco en el cual se efectúa es psicológico. El carácter del marco pasará a ser visto como social con Goffman.

Texto Digital, Florianópolis, Santa Catarina, Brasil, v. 11, n. 2, p. 71-90, jul./dez. 2015. ISSNe: 1807-9288. 
Goffman nos habla de la existencia en el juego de un framework primario, el cual se puede dividir en natural y social, estando ambas naturalezas interrelacionadas entre sí (GOFFMAN, 1986, p. 22). De este modo, la parte natural del marco se relaciona con la manipulación física, con sucesos no orientados e indirectos. Por otro lado, el marco primario social se sitúa en consonancia con eventos enfocados, orientados y motivados, es decir, con mundos donde los jugadores se pueden involucrar (GOFFMAN, 1986, pp. 22-23). Ambas naturalezas del marco son inseparables, puesto que para actuar en lo social es preciso interactuar con lo físico. ${ }^{2}$ El marco, por lo tanto, se vuelve social y compartido mediante la adquisición de significado, lo que es denominado por el autor como keying (GOFFMAN, 1986, pp. 43-45). Por medio de la key -set de convenciones- una actividad determinada, con un significado concreto dentro del marco primario, es transformada adquiriendo una significación diferente.

Goffman vuelve al ejemplo de los simios dado por Bateson para explicar como funciona este hecho. Así, un comportamiento de combate es transformado en un comportamiento lúdico, es decir, las acciones que se vinculan a una actividad seria se convierten en acciones relacionadas con el juego (GOFFMAN, 1986, pp. 41-42). Un poco más adelante, Goffman nos indica que el keying no solo funciona en el marco primario, sino que también puede darse sobre una key constituida mediante un proceso de keying previo, lo que es denominado por el autor como rekeying (GOFFMAN, 1986, pp. 79-81). Este concepto de transformación es fundamental para entender el Círculo Mágico, puesto que no solo va a aislar el espacio del juego, sino que también va a transformar la realidad y a dotarla de una nueva significación, constituyendo así nuevos marcos. Es, por lo tanto, por medio de la metacomunicación por la que se establece el contrato social entre los

2 La diferencia entre el marco natural y el marco social se entenderá mejor con un ejemplo indicado por Goffman en la página 23 de la obra citada. En un juego de damas podemos simplemente desplazar las piezas por el tablero o bien realizar un movimiento determinado en base a una estrategia establecida de antemano. El primer caso podríamos situarlo en el marco natural, donde el movimiento es puramente físico y no motivado. El segundo caso se enmarcaría en el social, puesto que estaría orientado hacia un objetivo concreto. Como se puede apreciar en el ejemplo, para poder efectuar la estrategia, es preciso partir del marco natural, es decir, del movimiento puramente físico, de forma que ambos marcos están muy próximos, mas solo se consigue la significación mediante el marco social. 
participantes que permite la transformación. En este sentido, cobran gran importancia los conceptos goffmianos reglas de la irrelevancia, recursos realizados y reglas de la transformación (vid. MONTOLA, 2012, pp. 49-51; STENROS, 2014, pp. 157-159). Mediante las reglas de la irrelevancia, todo lo que es externo al juego $-y$ que, por lo tanto, debe permanecer fuera del Círculo Mágico- es descartado e ignorado. En cuanto a las reglas de la transformación, estas son las que modifican el significado exógeno en endógeno al introducirse en el Círculo Mágico, es decir, por medio de las reglas de la transformación, elementos externos son introducidos en el juego con un cambio de su significación a un nivel ontológico.

La constitución del significado en tres niveles -exógeno, endógeno y diegético, siguiendo la terminología de Montola (MONTOLA, 2005, pp. 1-8)- está relacionada con los tres marcos o frames explicados por Alan Fine (FINE, 1983, pp. 185-186) a partir de Goffman. En el primary framework o social frame se sitúa el conocimiento que los participantes poseen del mundo real y que se relaciona con el juego y las personas. En este marco se sitúan los elementos exógenos. Por medio del contexto de juego y de las reglas, estos adquieren significado endógeno, pues se situarían en relación con la estructura, los componentes formales y los jugadores, constituyéndose así el segundo marco, denominado game frame. Finalmente, en el tercero, el fantasy frame o gaming-world frame, encontramos la significación diegética, puesto que los elementos endógenos se insertarían en el mundo ficcional por medio del conocimiento como personaje, siendo abandonada la identidad del jugador. El paso de un marco a otro -keyinges habitual a lo largo del juego y esto es posible debido a la permeabilidad del Círculo Mágico.

El Círculo Mágico va a ser fundamental, además, para comprender el concepto de Suits de lusory attitude (vid. SALEN Y ZIMMERMAN, 2004, pp. 97-98), que se refiere al estado mental del participante, mediante el cual se adoptan las reglas requeridas en un juego concreto para conseguir un objetivo en detrimento de la eficiencia, relacionándose así con el contrato social que se establece entre los 
jugadores y oponiéndose al concepto de hacer trampas. Salen y Zimmerman (SALEN Y ZIMMERMAN, 2004, p. 97) recogen un ejemplo de Suits a este respecto: en un combate de boxeo el objetivo es vencer al contrincante. Para conseguirlo, lo más eficiente sería emplear un arma de fuego, pues el combatiente que la manejase podría ganar sin necesidad de acercarse al contrario. Sin embargo, por medio de la lusory attitude, los jugadores aceptan las reglas aunque estas sean ineficientes e irracionales.

\section{La cuestión narrativa en The Stanley Parable: Stanley y el Narrador}

Para poder entender la complejidad de este juego debemos partir de la idea de videojuego como simulación (JUUL, 2001; FRASCA, 2003). Así, Gonzalo Frasca (FRASCA, 2003) parte del concepto de simulación computacional, ya apuntado por Aarseth en Cybertext (AARSETH, 1997), desposeyéndolo de las referencias a la máquina, pues no es preciso un entorno virtual para la existencia de simulación. ${ }^{3}$ De este modo determina que esta "is to model a (source) system through a different system which maintains to somebody some of the behaviors of the original system." (FRASCA, 2003, p. 223). Las simulaciones requieren de un sistema de input y output, por lo que se precisa la introducción de modificaciones por parte del jugador en el sistema -es decir, de interacción-, lo que provocará un cambio en el game state, que será devuelto a los participantes en forma de feedback. Esta es una diferencia fundamental con la literatura y el cine, cuyas secuencias semióticas son siempre idénticas, mientras que en los juegos estas serán diferentes cada vez que se reinicie el sistema, o dicho de otro modo, cada vez que se comience el juego. Por lo tanto, una de las principales características de los juegos es la inexistencia de narrador y narratario, lo que, sin duda, es una de las mayores diferencias entre los juegos y la narrativa tradicional. Esta peculiaridad debe relacionarse con la inmediatez y la efimeridad del texto que surge de los juegos.

Así, en los juegos, el emisor y el receptor del texto coinciden en la figura del

3 Cualquier juego, independientemente del medio, debe ser entendido como simulación.

Texto Digital, Florianópolis, Santa Catarina, Brasil, v. 11, n. 2, p. 71-90, jul./dez. 2015. ISSNe: 1807-9288. 
jugador (PADOL, 1996; MURRAY, 1999, p. 53; KIM, 2004, pp. 34-35; HELIÖ, 2004, p. 68), desapareciendo del texto el pasado narrativo. El texto, pues, se va creando en el presente inmediato a medida que el jugador va interactuando en tiempo real con el game frame. De este modo, inmediatez e interacción se sitúan muy cerca, surgiendo la primera a partir de la segunda. Esto provoca que el texto de un juego no pueda ser reproducido, puesto que cualquier juego implica una multiplicidad de textos potenciales. La inmediatez y la multiplicidad de textos potenciales no deben ser confundidos con lo que Janet Murray denomina historia multiforme, la cual es definida por la autora como "una obra escrita o dramática, que presenta una única situación o argumento en múltiples versiones, versiones que serían mutuamente excluyentes en nuestra experiencia común" (MURRAY, 1999, pp. 41-42), es decir, textos tradicionales en los que se muestra una situación desde diversas posibilidades de destino. La historia multiforme implica crear textos alternativos sobre una misma realidad, los cuales no tienen porque ser necesariamente inmediatos. ${ }^{4}$ Janet Murray relaciona las historias multiformes con los textos de los juegos debido a que estos son excluyentes de una partida a otra, es decir, en los juegos tendremos una multiplicidad de textos potenciales, la cual se irá reduciendo a medida que el jugador interaccione con el algoritmo y se vaya constituyendo el texto en el presente inmediato.

Sin embargo, The Stanley Parable está mucho más cercano a la historia multiforme que explica Murray en su obra que la mayoría de los juegos. Esto es porque en el juego se desarrollarán todas las posibilidades de la historia, las cuales son necesariamente excluyentes entre sí. Cada vez que el jugador llega a uno de los finales, el juego se reinicia con diferencias en el espacio, los objetos o en la voz del Narrador. Estas diferencias son sutiles en los primeros reinicios, pero a cada nuevo comienzo se hacen más evidentes. De este modo nos encontramos ante una historia que incluye muchas historias, con un comienzo -casi- idéntico

$4 \quad$ Podemos poner como ejemplo el capítulo 11 de la séptima temporada de Star Trek: The Next Generation, titulado Parallels (Wiemer, 1993), en el cual el Teniente Worf traspasa una brecha espacio-temporal cuando regresa de Forcas III a la Enterprise, provocando saltos entre universos paralelos, con las consiguientes realidades alternativas y cambios, en ocasiones casi inapreciables entre ellas, por lo que se muestran circunstancias excluyentes de uno a otro universo.

Texto Digital, Florianópolis, Santa Catarina, Brasil, v. 11, n. 2, p. 71-90, jul./dez. 2015. ISSNe: 1807-9288. 
pero con desarrollos y finales muy diferentes entre sí. Estamos, pues, ante una metahistoria orquestada por el Narrador, quien no duda en culpar a Stanley (o incluso al jugador) de que la narración no se desenvuelva como la tenía prevista, lo que sugiere un constante cambio en los frames del Círculo Mágico, como explicaremos un poco más adelante.

La estructura interactiva de este juego puede relacionarse con la teoría de la interactividad expuesta por Marie-Laure Ryan, quien nos indica que "digital texts are like an onion made of different layers of skin, and that interactivity can affect different levels." (RYAN, 2005). De esta manera, en The Stanley Parable podemos observar una estructura interactiva semejante a la hipertextual, donde "the materials that constitute the story are still fully predetermined, but thanks to the text's interactive mechanisms, their presentation to the user is highly variable." (RYAN, 2005). De esta manera, Ryan relaciona la estructura con un laberinto, donde todos los nodos están unidos entre sí con un nodo central -el cual, en este juego, es la oficina de Stanley-, de manera que se genera un bucle en la historia (fig.1):

The formal characteristic of the network structure is the existence of loops that offer several different ways to get to the same node. These loops make it possible to circle forever in the network. This explains why the image of the labyrinth and the notion of "book without end" play such an important role in hypertext theory. (RYAN, 2005)

Fig.1. Estructura laberíntica. (RYAN, 2005)

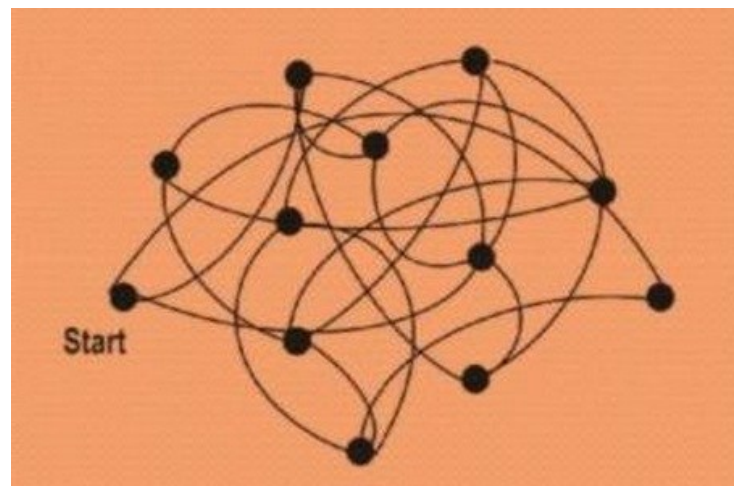

Por lo tanto, cada final implica automáticamente un nuevo inicio -no en vano 
aparece en la pantalla la frase "the end is never the end" durante cada recarga-, sin que ello suponga una nueva historia, sino su continuación. Además, el jugador podrá reiniciar el juego siempre que quiera, lo que provocará nuevos cambios en el espacio o en las opciones de interacción disponibles. De esta manera, vemos como en The Stanley Parable se esconde un árbol de decisiones (fig. 2): ciertas elecciones por parte del jugador condicionarán lo que suceda en adelante hasta producir distintos desenlaces, mientas que otras modificaciones semejan arbitrarias y no motivadas. Esto es muy habitual en los videojuegos, especialmente en los RPGs, donde la posibilidad de diversas elecciones por parte del jugador construye una historia determinada, otorgando de este modo una falsa ilusión de libertad. En este caso, esa sensación de libertad es el centro del juego, y esta es cuestionada continuamente por diversos medios: por las escasas posibilidades de interacción con el entorno y la ausencia de PNJs, ${ }^{5}$ por las críticas del Narrador al no seguir la narración y contravenir su autoridad como creador de la línea argumental, o por la propia estructura de la historia, la cual se construye

$5 \mathrm{Si}$ el jugador decide interaccionar con los ordenadores y los teléfonos de los puestos de trabajo nada más salir Stanley de su oficina, el Narrador indicará "Stanley anduvo tocando cada pequeña cosa en la oficina, pero eso no hacía diferencia alguna, ni hacía que la historia avance de ninguna forma." Si intenta abrir las puertas de las oficinas, el Narrador dirá: "Stanley clikleó literalmente cada puerta en la oficina, porque no capta de todo las indicaciones de su entorno." En relación con esto, cabe destacar el hecho de que las mecánicas del juego son extremadamente sencillas, estando limitadas a la elección del camino a tomar y a unas escasísimas posibilidades de manipular objetos en algunos de los reinicios. Así pues, The Stanley Parable no se caracteriza por sus mecánicas -o, en todo caso, lo hace por la sencillez de las mismas-, sino por unas estéticas novedosas y rupturistas respecto a las habituales en los videojuegos. En contraste con la mayoría de los juegos, aquí no existen condiciones para la victoria, por lo que el objetivo no es ganar, sino disfrutar de la experiencia de juego, siendo esto último lo que le otorga su significación. 
Fig. 2. El árbol de decisiones. Cada final supone un regreso al inicio, marcado como START



de manera rizomática, como un bucle en el que debemos tomar una y otra vez las mismas decisiones para poder ir descubriendo la complejidad del juego. Sin embargo, debe tenerse en cuenta que no se niega la existencia de interacción, sino que se cuestiona la misma. Esto debe entenderse en relación con el algoritmo de los videojuegos y la cuestión de la progresión o la emergencia, y como de esta diferencia puede surgir una mayor libertad para el jugador. Esta reflexión se observa en el momento en el que el jugador decide desconectar de la línea el teléfono que suena. El Narrador entonces indica que esa opción no estaba contemplada en la historia -evidentemente, sí lo estaba-, y acusa a Stanley de no ser un personaje, de estar manejado por una persona real, provocando, por lo tanto, un cambio de frame mediante el proceso de rekeying 
anteriormente explicado. Este tipo de reflexiones sobre los videojuegos son constantes, no solo en las disertaciones del Narrador, sino también en los elementos que se pueden observar en el espacio, muchos de los cuales -hojas de papel tiradas en el suelo, pizarras, etc.- son pequeños detalles que pueden pasar desapercibidos si no se observan con atención. Estos no provocan un cambio en los finales, sino que son objetos que causan una comicidad intertextual al referirse a otros juegos o películas. ${ }^{6}$ La intertextualidad en The Stanley Parable debe ser entendida como un recurso para la reflexión del medio y del lenguaje videolúdico, formando así parte del metajuego que impregna todo el título. De hecho, Stanley llegará a estar en el mundo de Minecraft (MOJANG AB, 2011) o en las instalaciones de Aperture Science (Portal, VALVE, 2007), en donde podrá realizar uno de los puzzles de este juego, modificándose de esta manera las mecánicas y objetivos de The Stanley Parable por los de este título.

De esta manera, el juego no se basa en tomar una serie de decisiones para llegar a un final cerrado, sino en realizar las mismas elecciones una y otra vez, con pequeñas variaciones entre ellas, para poder explorar la totalidad de la narración. Así, un final no invalida los demás, sino que puede propiciarlos. Por medio de esa narración se establece un proceso de metacomunicación constante entre el jugador y el propio juego, a través de la voz del Narrador, con la intención de que el jugador reflexione sobre el lenguaje de los videojuegos y entrevea la complejidad y las contradicciones que tan a menudo se observan en los juegos. The Stanley Parable es un ejemplo magistral de metajuego, y debe ser entendido como cibertexto en el sentido otorgado por Aarseth: una máquina productora de textos (AARSETH, 2004, p.119).

Los frames de Bateson y Goffman son fácilmente reconocibles en The Stanley Parable. De hecho, la comicidad y la crítica en este título proviene de la confluencia de los frames y del constante proceso de keying que se produce durante el juego. Sin embargo y a diferencia de la mayoría de los videojuegos,

6 La red intertextual de The Stanley Parable es extensa, llegando a hacerse referencia a juegos como Minecraft (MOJANG AB, 2013), Portal (VALVE, 2007), Papers, please! (LUCAS POPE, 2013), Quake II (ID SOFTWARE, 1997), o a películas como 2001: Una odisea en el espacio (KUBRICK, 1968).

Texto Digital, Florianópolis, Santa Catarina, Brasil, v. 11, n. 2, p. 71-90, jul./dez. 2015. ISSNe: 1807-9288. 
aquí el marco diegético que constituye el contexto y la historia no supone el centro del juego. Es el punto de inicio para establecer la subversión del mismo mediante las acciones del jugador y negar de esta manera la autoridad del Narrador sobre el texto. Así, el jugador deja de ser Stanley en el mismo momento en que decide ignorar las instrucciones del Narrador -al fin y al cabo un personaje como tal no puede llevar la contraria a la supuesta voz autorial-, pasando a interpretarse a sí mismo, es decir a un jugador que maneja el avatar de un personaje llamado Stanley. De esta manera observamos como se produce un cambio de frame y una modificación del Círculo Mágico, pero no una ruptura del mismo, pues la mentalidad lúdica establecida como contrato social al inicio del juego se mantiene y se adapta a las nuevas circunstancias, así como al nuevo marco ontológico. En este sentido se pone de manifiesto el segundo frame, relacionado con las reglas, por medio de la ruptura narrativa y de las continuas referencias del Narrador a las mecánicas y dinámicas del juego. Así pues, nos encontramos con una situación que, como jugadores, encontramos hilarante por ser completamente nueva en un juego, aunque no en la literatura: un narrador que, si seguimos la terminología narratológica, podríamos denominar en un comienzo como heterodiegético omnisciente, subvierte su propia naturaleza debido a la agencia del jugador -la que, en un principio, es negada por el mismo narrador con el consentimiento del jugador-, y se transforma por medio de una metalepsis narrativa en personaje. ${ }^{7}$ Nótese que anteriormente hemos indicado que una de las características de los juegos es la ausencia de narrador y narratario, debido a su carácter inmediato. En este sentido cabe destacar que la figura del Narrador en The Stanley Parable no contradice este hecho, pues este, como estamos diciendo, es construido como personaje perteneciente a la diégesis del texto y no como una voz autorial. De

7 Son muy interesantes dos de los finales del juego, el denominado museum ending y el confusion ending por mostrarnos la naturaleza de personaje del Narrador. En el primero surge una segunda voz narrativa, la Narradora, que nos muestra como claramente el Narrador es un personaje más de la historia: "Adios, Stanley, clamó el Narrador, mientras Stanley era llevado con impotencia hacia las enormes mandíbulas de metal". En the confusion ending, por otra parte, Stanley y el Narrador llegan a una habitación llena de monitores en los que se muestran las acciones del Narrador y los reinicios del juego que este ha efectuado, así como el tiempo restante para el siguiente reinicio. De este modo nos muestra que su autoridad sobre el juego no es tal y que es, por lo tanto, un personaje que sigue un guión prefijado, aunque él lo desconozca. De hecho, ante esta pantalla, el Narrador indica: "No, no puede ser. No quiero que el juego siga reiniciándose. No quiero olvidar lo que está ocurriendo. No quiero estar atrapado así. No reiniciaré el juego. ¡No lo haré! ¡No lo haré! No lo haré.” 
hecho, esta contradicción es una de las características más interesantes del título, por cuanto, como ya se ha apuntado, se pretende mostrar como la agencia del jugador es primordial en los juegos, en contraste con la narración tradicional donde el lector/espectador es conducido en una historia inamovible.

De esta manera, las referencias constantes a las reglas y a la historia como tal pasan de lo que podemos denominar segundo frame al tercero, construyendo una diégesis fuera de la narración, convertida en metajuego. La significación, de este modo, se adquiere por medio de la consciencia del jugador de estar interpretándose a sí mismo, quien, como se ha dicho, es acusado por el Narrador de ser una persona real y es denominado en diversas ocasiones como jugador. La consciencia de pertenecer a un juego por parte del Narrador y del jugador, y que, por lo tanto, todo lo vivido es una construcción artificial, no provoca una ruptura del Círculo Mágico, sino que causa una modificación del mismo. Vamos a observar, por lo tanto, un cambio prácticamente constante entre el game frame y el fantasy game, de manera que lleguen a relacionarse de una manera directa y el segundo desaparezca en aras del primero. Esto es porque, como hemos dicho anteriormente, The Stanley Parable no es un videojuego al uso. La historia que nos cuenta, si seguimos las instrucciones del Narrador, carece de importancia en este título $\mathrm{y}$, de hecho, se muestra cierta ironía en que la historia sobre como Stanley consiguió liberarse del control mental y adquirir su libertad se construya siguiendo las indicaciones del Narrador, sin poder subvertirlas en ningún momento. Sin embargo The Stanley Parable sí es un juego sobre la libertad y la agencia de los jugadores a la hora de enfrentarse a las diversas decisiones que se deben tomar en un videojuego. Es, por lo tanto, un título que explora desde el humor las mecánicas y dinámicas, así como la cuestión autorial.

El concepto de lusory attitude antes explicado, que se debe relacionar con el primero y el segundo frame por cuanto supone la aceptación de las reglas y el sometimiento a las mismas sin cuestionarlas, también puede verse reflejado en este título, no solo en las referencias del Narrador a la capacidad de Stanley para romper la historia -lo que, sin duda, no es posible-, sino también en el empleo de 
la consola de comandos, lo que la mayoría de las compañías de videojuegos actuales permiten y facilitan. Esto es aprovechado para realizar una reflexión y una crítica sobre su uso en los videojuegos. El jugador podrá, si lo desea, activar dicha consola, de modo que, al hacerlo, el Narrador acusará al jugador de efectuar trampas y lo llevará a la que denomina la habitación seria para mantenerlo castigado en una mesa. ${ }^{8}$ Esto resulta muy interesante, por cuanto la consola de comandos implica modificaciones en el código del juego con el fin de adquirir cierta ventaja que tiende a desestabilizar la proporción de dificultad, por lo que habitualmente la modificación del código equivale a hacer trampas -no en vano se denominan cheat codes a los comandos empleados para ello-. El empleo de este tipo de cheat codes supone un nuevo cambio de frame del Círculo Mágico, pues para su utilización es preciso pasar del tercer marco de realidad ontológica al primero, empleando para ello la metacomunicación con el sistema, lo que supone una modificación del segundo marco. Para realizarlo es imprescindible salir del juego, por cuanto el empleo de la consola de comandos supone la estaticidad del universo ficcional mientras se maneja. Sin embargo, en el caso de este título, dicho uso no conlleva una ruptura con el fantasy frame, sino que forma parte de él, pues supone una modificación en el estado del Narrador, lo que conllevará a un final determinado. De esta manera vemos de nuevo como por medio del metajuego se pone de manifiesto la construcción de una nueva manera de conducir una historia, lo que dista notablemente de la narrativa tradicional, resaltando los entresijos del lenguaje videolúdico mediante la importancia de la interacción del jugador con las reglas del juego en un entorno simulado.

\section{Conclusión}

The Stanley Parable nos presenta un mundo ficcional en el que el jugador simula ser un jugador que maneja un personaje. Es decir, el jugador es sí mismo. Esta ruptura jugador/Stanley es evidente a través de la figura del Narrador, quien no es más que un personaje -lo que queda demostrado a través de la figura de la

$8 \mathrm{Al}$ hacer esto, el Narrador le indicará a Stanley: "Acabas de intentar activar las trampas de servidor, lo cual por supuesto corre el riesgo de romper el juego entero. Tú no tienes respeto por el estricto orden de los eventos narrativos por guión y no puedo aguantar esto."

Texto Digital, Florianópolis, Santa Catarina, Brasil, v. 11, n. 2, p. 71-90, jul./dez. 2015. ISSNe: 1807-9288. 
Narradora, o por el confusion ending-. El Narrador -en principio- semeja ser omnisciente, pues parece conocer los pensamientos de Stanley, así como lo que hará. Es decir, está construido como un narrador onmisciente clásico, que narra las andanzas de un personaje en una historia de la cual el narrador conoce toda la verdad argumental, de los personajes y del mundo ficcional. Sin embargo, esto es alterado debido a que Stanley no es un personaje, es un jugador y, por lo tanto, posee la capacidad para modificar la narración por medio de la agencia. De esta manera, se producen constantes cambios en los frames del Círculo Mágico, siendo el jugador el primero en romper con la narración al desoír al Narrador. Así, el personaje de Stanley se vuelve autónomo, es decir, deja de ser un personaje sometido a una narración tradicional y pasa a ser agente en cuanto desobedece las instrucciones del Narrador y comienza a llevar a cabo sus propias decisiones, haciéndose patente la figura del jugador como tal. De esta manera podemos observar una clara dicotomía entre la historia narrada por el Narrador, la cual se construye como una narración tradicional en un medio virtual, lo que podríamos denominar Novela Digital, con un comienzo, un nudo y un desenlace que siempre son iguales y donde el jugador únicamente debe seguir las instrucciones del narrador para llevar a buen término la historia, y las acciones de Stanley. Así, el jugador puede -y debe- romper con el modelo tradicional de narración y revelarse contra la autoridad autorial sustentada por la voz del Narrador, de manera que se muestra la realidad del medio virtual, la ruptura con los modelos tradicionales de narración y la aparición de un nuevo objeto, el videojuego, donde, como se ha dicho, desaparece la división entre emisor y receptor, confluyendo ambos en la figura del jugador. Este, por medio de la agencia, será quién de construir en el presente un texto inmediato y efímero. A partir de ese momento, The Stanley Parable nos muestra con mucho humor como los videojuegos se alejan de la narrativa tradicional y como poseen un nuevo lenguaje que ha terminado por construir sus propios clichés, aceptados por diseñadores y jugadores, los que los perpetúan. Esto es el que el Narrador nos muestra: los clichés, el nuevo lenguaje, como se repiten en los diversos juegos, como es algo comprensible para los jugadores debido a ello, y como, por lo tanto, se espera que se produzcan ciertas situaciones frente a otras. De este modo, The Stanley 
Parable nos propone como tema la diferencia entre la narrativa tradicional y los juegos, entendidos estos como mundos simulativos en los que es precisa la agencia del jugador para poder desenvolverse la simulación. Además, nos muestra una batalla entre ambos lenguajes -el de la narrativa lineal y el de los videojuegos- por medio de la figura del Narrador, quien se considera a sí mismo autoridad en la historia y la narrativa, y de Stanley, quien no es más que el alter ego del jugador, una persona del mundo real que manipula la historia del Narrador por medio de sus acciones, interaccionando con el mundo simulado. Este choque entre el Narrador y Stanley hace surgir el metajuego y The Stanley Parable se convierte en una crítica y homenaje al lenguaje videolúdico. Nótese, pues, la importancia de la ergocidad: el jugador es quién de estropear la narrativa del Narrador al escoger realizar ciertas acciones frente a otras. Esta idea es insinuada en diversos momentos del juego, y resulta realmente interesante su planteamiento en un título como este, pues absolutamente todos los finales y las acciones permitidas están previstas por el algoritmo. Sin embargo, las palabras del Narrador tienden a implicar que, por causa del jugador, el juego o la narración se ha estropeado. De esta manera, podemos comprobar como se hacen visibles las mecánicas y dinámicas del juego, produciéndose un cambio en la realidad inmediata sin que por ello se llegue a romper el Círculo Mágico. Por lo tanto, el jugador será consciente de la ficcionalidad del mundo, así como del personaje de Stanley, y pasará a representar a una persona real, capaz de reiniciar el juego si así lo desea, sin que ello suponga un nuevo comienzo. Esta dualidad entre jugador/personaje, como se ha dicho, es potenciada a través del Narrador, provocando un continuo proceso de keying durante el juego.

Las mecánicas del juego son muy sencillas, y las oportunidades de interacción son mínimas, lo que tiende a ser muy habitual en los videojuegos, donde apretando un botón podemos realizar acciones complejas. En este título ocurre lo mismo, y la más mínima interacción puede modificar el final de la historia o su transcurso. La ironía que el Narrador muestra al hacer referencia a las mecánicas y clichés de los videojuegos es magistral, y, por medio de este humor, el autor pretende hacernos reflexionar sobre los tópicos y las mecánicas en los juegos. 
The Stanley Parable es un juego sobre juegos, sobre el lenguaje de estos y sobre la figura del jugador como tal, su actividad, su ergodicidad y su agencia.

\section{METAGAME AND SUBVERSION OF TRADITIONAL NARRATIVE IN THE STANLEY PARABLE}

ABSTRACT: The Stanley Parable is a masterful example of metagame, whereby is made a parodic reflection on the videogame language and its difference from the traditional narrative. This paper intends to perform an approach to the central theme of this title -metagame and interactivity of player-, based on the theory of ontological frames and the constitution of the Magic Circle through these. In this way, we will check as it occurs a constant changing of reality frames through the Narrator's voice, by means of which we can see the player/character dichotomy marked by the agency.

KEYWORDS: Metagame. Game Studies. Ludology. Magic Circle. The Stanley Parable.

\section{O METAGAME E A SUBVERSÃO DA NARRATIVA TRADICIONAL EM THE STANLEY PARABLE}

RESUMO: The Stanley Parable é um exemplo magistral de metagame, no que é feita uma reflexão paródica sobre a linguagem do videogame e sua diferença em relação à narrativa tradicional. Este artigo tem como objetivo realizar uma abordagem para o tema central deste título - o metagame e interatividade do player-, partindo, para isto, da teoria dos frames ontológicos e da constituição do Círculo Mágico através deles. Desta forma, vamos verificar como ocorre uma modificação do frame de realidade através da voz do Narrador, pelo qual podemos ver a dicotomia jogador/personagem marcado pela agência.

PALAVRAS-CHAVE: Metagame. Game Studies. Ludologia. Círculo Mágico. The Stanley Parable.

\section{Referencias bibliográficas:}

AARSETH, Espen. Cybertext. Perspectives on Ergodic Literature. Baltimor: The Johns Hopkins University Press, 1997.

AARSETH, Espen. La literatura ergódica. Sánchez-Mesa, D. (ed.). Literatura y Cibercultura, Madrid: Arco Libros, 2004. pp. 117-145. 
BATESON, Gregory. A Theory of Play and Fantasy, Steps to an Ecology of Mind. New Jersey: Jason Aronson Inc., 1987. pp. 183-198.

FINE, Alan Gary. Shared Fantasy. Role-Playing Games as Social Worlds. Chicago: The University of Chicago Press, 1983.

FRASCA, Gonzalo (2003). Simulation versus Narrative: Introduction to Ludology. Wolf, J. P. Mark, y Perron, Bernard (eds), Video Game Theory Reader. New York: Routledge, 2003, pp. 221-236. Online en: <http://www.ludology.org/articles/VGT_final.pdf>. Consultado en 2015.

GOFFMAN, Erving. Frame Analysis. An Essay on the Organization of Experience. Boston: Northeastern University Press, 1986.

HELIÖ, Satu. Role-Playing: A Narrative Experience and a Mindset, Montola, Markus, y Stenros, Jaakko, (eds). Beyond Role and Play. Tools, Toys and Theory for Harnessing the Imagination. Helsinki: Fëa Livia, 2004, pp. 65-74.

JUUL, Jesper. Games Telling stories? A brief note on games and narratives. Game Studies, V. 1, N. 1, 2001. Online en: <http://www.gamestudies.org/0101/juul-gts/>. Consultado en 2015.

KIM, John H. Immersive Story. A View of Role-Played Drama. Montola, Markus y Stenros, Jaakko, (eds). Beyond Role and Play. Tools, Toys and Theory for Harnessing the Imagination. Helsinki: Fëa Livia, Helsinki, 2004. pp. 31-38

MONTOLA, Markus, (2005): Designing Goals for Online Role-Players. Proceedings of DiGRA. International Conference. Changing Views: Worlds in Play. Vancuver, junio 16-20, 2005. Online en: <http://www.pervasivegaming.org/Publications/Designing-Goals-for-Online-Role-Players.pdf>. Consultado en 2005. 
MONTOLA, Markus. On the Edge of the Magic Circle. Understanding Role-Playing and Pervasive Games. Tampere: University of Tampere. 2012. Online en: <http://tampub.uta.fi/handle/10024/66937>. Consultado en 2015.

MURRAY, Janet. Hamlet en la Holocubierta. El futuro de la narrativa en el ciberespacio. Barcelona: Paidós, 1999.

PADOL, Lisa. Playing Stories, Telling Games: Collaborative Storytelling in RolePlaying Games. RECAP: Publications, V. 199. 1996. Online en <http://www.labcats.org/drcpunk/wiki/index.php/Playing_Stories,_Telling_Games>

RYAN, Marie-Laure . Peeling the Onion: Layers of Interactivity in Digital Narrative Texts. Conferencia en Münster, Germany, Mayo, 2005 . Online en: $<$ http://users.frii.com/mlryan/onion.htm>. Consultado en 2015.

SALEN, Katie, y ZIMMERMAN, Eric. Rules of play. Game design fundamentals, Massachusetts: The MIT Press, 2004.

STENROS, Jaakko. In defence of a Magic Circle: The Social, Mental and Cultural Boundaries of Play. Transactions of Digital Games Research Association (DiGRA), V. 1, N. 2, 20014, pp. 147-185. Online en <http://www.digra.org/wpcontent/uploads/digitallibrary/12168.43543.pdf>. Consultado en 2015.

\section{Referencias ludográficas:}

Minecraft (Mojang AB, 2011)

Papers, please! (Lucas Pope, 2013)

Portal (Valve, 2007)

Quake II (id Software, 1997)

The Stanley Parable (Galactic Cafe, 2013) 


\section{Referencias filmográficas:}

2001: Una odisea en el espacio (Kubrick, Stanley, 1968)

Star Trek: The Next Generation, cap.11, temp.7, Parallels (Wiemer, 1993)

Recebido em: 12/08/2015.

Aceito em: 02/12/2015. 